\title{
Determination of Manganese in Environmental Samples by UV-Vis after Cloud Point Extraction
}

\author{
Xiupei Yang*, Gu Li, Xiaocui Yang, Zhihui Jia and Na Luo \\ College of Chemistry and Chemical Engineering, Chemical Synthesis and Pollution Control Key Laboratory of Sichuan Province, \\ China West Normal University, Nanchong 637000, China \\ *Corresponding author
}

\begin{abstract}
Cloud point extraction was used with 1-(2-pyridylazo)2-naphthol (PAN) as a pre-concentration step prior to UV-vis spectrophotometer determination of trace amounts of manganese in water samples. The process is based upon the formation of Mn( II )/PAN complexes soluble in a micellar phase composed by the non-ionic surfactant Triton X-114 (octylphenoxy polyethoxyethanol). Trace Mn(II) /PAN complexes followed by UV-vis spectrophotometer measurement. In this proposed procedure, when above its cloud point temperature, these complexes are then extracted into the surfactant-rich phase. The parameters affecting the extraction efficiency, i.e. $\mathrm{pH}$ of aqueous solution, concentration of the PAN, amount of the surfactant, incubation temperature, and incubation time were investigated. The calibration graph was linear in the range $15-500 \mathrm{ng} \cdot \mathrm{mL}^{-1}$ with a limit of detection (LOD) of $5 \mathrm{ng} \cdot \mathrm{ml}^{-1}$. The proposed method was successfully applied for the determination of trace manganese in various water and soil samples.
\end{abstract}

Keywords-cloud point extraction; manganese; ultravioletvisible spectroscopy

\section{INTRODUCTION}

Manganese $(\mathrm{Mn})$ is an indispensability for the appropriate function of a few enzymes and a necessary micro-nutrient for the function of the brain, nervous system, and normal bone growth. Enzyme and membrane transport functions are optimized by manganese [1-3]. Mn is a necessary trace element which can be appeared in several food varieties such as tea, grain, rice, soya bean, egg, nut and cereal. Some organisms such as diatoms, mollusca and sponge animal can accumulate manganese element [4]. However, superfluous levels of Mn are harmful to the body, giving rise to poisonousness to central nervous system, respiratory system, and reproductive system. Human who exist in a high concentration of manganese ion in the environment for a long-term can cause interference of mental and emotions and slow, clumsy physical actions [5]. Therefore, it is important to determinate the trace amounts of $\mathrm{Mn}$ in various matrices samples for certain areas, such as environmental chemistry and food processing [6].

Determination of the trace amounts $\mathrm{Mn}$ in environmental sample or biological sample is very difficult due to many kinds of influence factors. UV-vis spectrophotometry is a useful analytical method for determination trace amounts of elements in environmental matrices sample. However, preconcentration and separation of $\mathrm{Mn}$ and iron is still essential, the correlation processing techniques such as liquid-liquid extraction [7], co- precipitation [8], solid-phase extraction [9-11] and cloud point extraction [12].

Separation and preconcentration of cloud point extraction (CPE) are becoming a significant and actual application of surfactants in analytical chemistry [13-15]. Cloud point extraction technology is a new type of liquid-liquid extraction technology [16]. It depends on the solubilization phenomena and cloud point character of surfactant in aqueous solution to take shape micelles and separate two phase. One phase is a surfactant-rich phase of little volume, and another phase is diluted aqueous phase of a large volume when the surfactant solution is heated to a certain temperature so-called cloud point temperature. The hydrophobic compounds originally existing in the sample solution and bound to the micelles are extracted to the surfactant-rich phase. The little volume of surfactant-rich phase of getting from cloud point extraction allows the design of extraction methods that are simple, speedy, cheap, efficient and low toxicity to environment compared with the general liquid-liquid extraction technology. This separation technology has gained a great deal of attention, because the cloud point extraction technology has great potential to separate toxic matrix samples.

In the present work, we study a kind of simple, high sensitivity and high selectivity of cloud point extraction to enrichment of trace amounts of manganese ion in environmental sample matrix and UVvis spectrophotometry has been used as quantitative assay of manganese ions. An analytical method was established which the PAN as complexing agent and the Triton X-114 as the surfactant. Trace amounts of manganese ion in environmental samples were extracted by the cloud point extraction.

\section{EXPERIMENTAL}

\section{A. Materials and Chemicals}

Stock standard solution of $1000 \mathrm{mg} \cdot \mathrm{L}^{-1} \mathrm{Mn}^{2+}$ was carefully prepared by dissolving $\mathrm{MnSO}_{4}$ in $2 \%(\mathrm{v} / \mathrm{v}) \mathrm{HNO}_{3}$. Working standard solutions were obtained daily by stepwise dilution from standard stock solution with Double Distilled water (DDW). The chelating reagent was prepared by dissolving PAN in $\mathrm{CH}_{3} \mathrm{CH}_{2} \mathrm{OH}$ with a final DDTC concentration of $4 \times 10^{-3} \mathrm{~mol} \cdot \mathrm{L}^{-1}$. The non-ionic surfactant Triton X-114 purchased from Aladdin was used in this work with a final Triton X-114 concentration of $50 \mathrm{~g} / \mathrm{L}$. The desired $\mathrm{pH}$ of the solutions was adjusted by using $0.2 \mathrm{~mol} \cdot \mathrm{L}^{-1} \mathrm{NH}_{3} \cdot \mathrm{H}_{2} \mathrm{O}$ and 0.2 $\mathrm{mol} \cdot \mathrm{L}^{-1} \mathrm{NH}_{4} \mathrm{Cl}$. DDW was used throughout the whole work. 


\section{B. Apparatus}

UV2550 ultraviolet and visible spectrophotometer (SHIMADZU) was used for quantitative analysis of manganese A centrifuge model TDZ5-WS (Shanghai Lu Xiangyi centrifuge Instrument Co., Ltd, Shanghai, China) was used to facilitate phase separation. The $\mathrm{pH}$ values were measured by Ohaus Starter 3C pH meter (Pine Brook, NJ, USA).

\section{Samples Preparation}

The soil was sampled from the mountain, gardens and fields that located in China West Normal University. The collection of soil used four points sampling method, and then these soil samples were dried at $120{ }^{\circ} \mathrm{C}$ for up to $24 \mathrm{~h}$ until constant dry weight was achieved. Soil sample was grinded with ceramic mortar and pick out chunks of rock and grassroots etc. Then sample was sieved with 100 mesh points. The samples were used for later analysis. Using tools such as mortar and sample points screen etc were washed cleanly with anhydrous ethanol before the sample processing. It can prevent the sample pollution to affect the results of the determination. A $5.0 \mathrm{~g}$ dried soil samples was weighted into a plastic tube and $0.1 \mathrm{~mol} / \mathrm{L} \mathrm{HCl}$ solution $(1: 10, \mathrm{v} / \mathrm{v})$ was added. The resulting mixture was subject to stirring evenly for overnight, followed by keeping in room temperature oscillation for $3 \mathrm{~h}$ and filtering. Then, three kinds of the acid leaching soil solutions were used for the subsequent analysis.

\section{Operating Procedure}

A certain amount of standard solution of manganese was taken in $10 \mathrm{~mL}$ centrifuge tube. Added $0.1 \mathrm{~mL}$ of $4 \times 10^{-3}$ $\mathrm{mol} \cdot \mathrm{L}^{-1}$ PAN solution, $0.8 \mathrm{~mL}$ of $\mathrm{pH}=9$ buffer solution and 1.0 $\mathrm{mL}$ of $50 \mathrm{~g} \cdot \mathrm{L}^{-1}$ Triton $\mathrm{X}-114$ solution. DDW was used as to ensure volume $10 \mathrm{~mL}$ and shaken well. The solution containing analyte was heated in the water bath at $50^{\circ} \mathrm{C}$ for $15 \mathrm{~min}$. Separation of the phases was achieved by centrifugation at $4000 \mathrm{rpm}$ for $10 \mathrm{~min}$. Then, it was cooled in an ice bath for 10 min to increase the viscosity of the surfactant-rich phase. The aqueous phases can readily be discarded by inverting the tube. Anhydrous ethanol was added to the surfactant-rich phase (200 $\mu \mathrm{L})$ to reduce its viscosity and to promote sample treatment prior to UV-vis spectrophotometer. Finally the solution $(3 \mathrm{~mL})$ was detected by UV-vis spectrophotometer. Blank solution was also operated a similar procedure and measured in parallel to the sample solutions.

\section{RESULTS AND DISCUSSION}

\section{A. Detection Wavelength}

According to the experimental methods after operation, a certain amount of manganese standard working solution was taken and detected absorption spectrum of solution under the UV-vis spectrophotometer. The results are showed in Fig.2 that solution's absorbance value was maximum when the detection wavelength at $553 \mathrm{~nm}$. Therefore, this experiment determined $553 \mathrm{~nm}$ as the best detection wavelength.

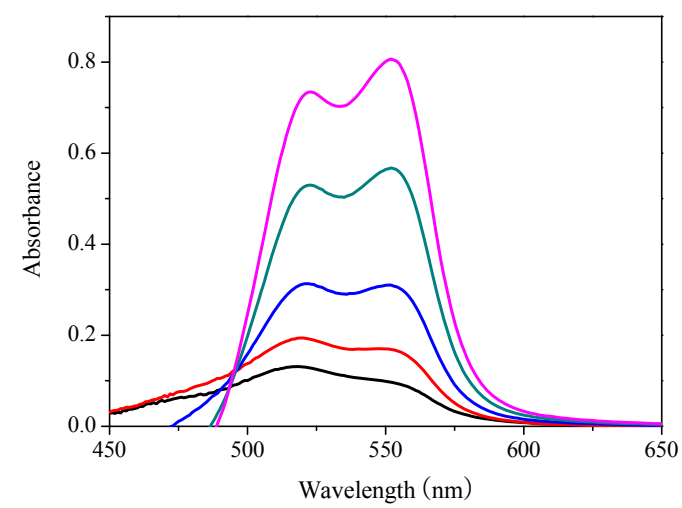

FIGURE I. ABSORPTION SPECTRUM OF MANGANESE STANDARD SOLUTIONS

\section{B. Effect of $p H$}

It needs appropriate complexing agent and metal ions to form hydrophobic complex when metal ions are extracted by the cloud point extraction. Then complex is extracted to surfactant phase and extraction rate depends on the acidity of complex formation solution. Therefore, the different $\mathrm{pH}$ has an effect on extraction rate of $\mathrm{Mn}^{2+}$. Cloud point extraction of $\mathrm{Mn}^{2+}$ was carried out in the $\mathrm{pH}$ range7-11. The results are shown in Fig. 3. The recovery of $\mathrm{Mn}^{2+}$ increased with increasing $\mathrm{pH}$ from 7 to 9 , and reached a maximum at $\mathrm{pH} 9.0$. Because the manganese and PAN can generated a stable complex in alkaline condition. Under the condition of alkali, it could be a problem for the hydrolysis of $\mathrm{Mn}^{2+}$. Taking into consideration of all these factors, $\mathrm{pH} 9.0$ was chosen for use in this work.

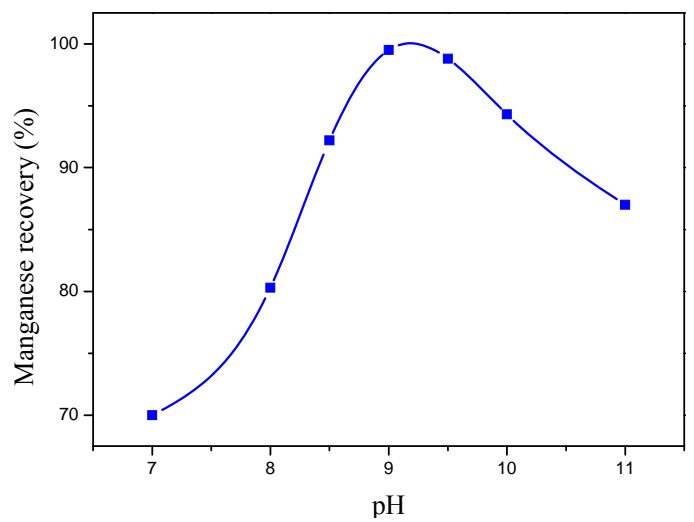

FIGURE II. EFFECT OF PH ON THE CLOUD POINT EXTRACTION OF $\mathrm{MN}^{2+}\left(100 \mathrm{NG} \cdot \mathrm{ML}^{-1}\right)$. EXPERIMENTAL CONDITIONS: $0.5 \%(\mathrm{~V} / \mathrm{V})$ TRITON X-114 AND $4 \times 10-5 \mathrm{MOL} \cdot \mathrm{L}^{-1} \mathrm{PAN}$.

\section{Volume of the PAN}

Chelating agent is one of the key factors influence the extraction efficiency. As shown in Fig. 4, cloud point extraction of $\mathrm{Mn}^{2+}$ was carried out in the volume of the PAN range $0.04-0.16 \mathrm{~mL}$. The recovery of $\mathrm{Mn}^{2+}$ increased with increasing of PAN volume from 0.04 to $0.10 \mathrm{~mL}$, and reached a maximum at PAN volume $0.10 \mathrm{~mL}$. However, when PAN volume is higher than $0.10 \mathrm{~mL}$, extraction rate declined. It could be excessive free PAN into the surfactant-rich phase and 
lead to $\mathrm{Mn}^{2+}$ was replaced by PAN, then $\mathrm{Mn}^{2+}$ entered into main water phase. Taking into account all these factors, volume of the PAN $0.10 \mathrm{~mL}$ was chosen for use in this work.

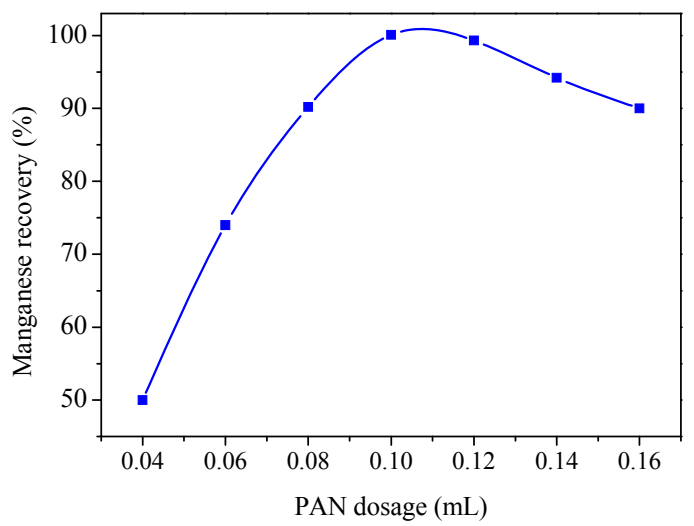

FIGURE III. EXTRACTION EFFICIENCY OF THE COMPLEX AS A FUNCTION OF VOLUME OF THE PAN. EXPERIMENTAL CONDITIONS: $\mathrm{MN}^{2+}\left(100 \mathrm{NG} \cdot \mathrm{ML}^{-1}\right), 0.5 \%(\mathrm{~V} / \mathrm{V})$ TRITON X-114 AND PH 9.

\section{Concentration of Triton $X-114$}

Triton X-114 is one of the non-ionic surfactant extensively used in CPE. Because that is its benefits such as commercial availability with high purity, low toxicity and cost, high density of the surfactant-rich phase can promote the phase separation by centrifugation, and relatively low cloud point temperature. As shown in Fig. 5, cloud point extraction of $\mathrm{Mn}^{2+}$ was carried out in the Triton X-114 concentration range $0.2-1.0 \%(\mathrm{v} / \mathrm{v})$. The recovery of $\mathrm{Mn}^{2+}$ increased with increasing of Triton X114 concentration from $0.2 \%$ to $0.5 \%$, and reached a maximum at Triton X-114 concentration $0.5 \%$. However, when Triton X114 concentration is higher than $0.5 \%$, extraction rate was invariant. This showed that the quantity of enough TritonX-114 can ensure the chelate extracted absolutely to ensure the extraction complete and improve the measurement sensitivity. Thus, a concentration of $0.5 \%(\mathrm{v} / \mathrm{v})$ Triton X-114 was used for subsequent experiments.

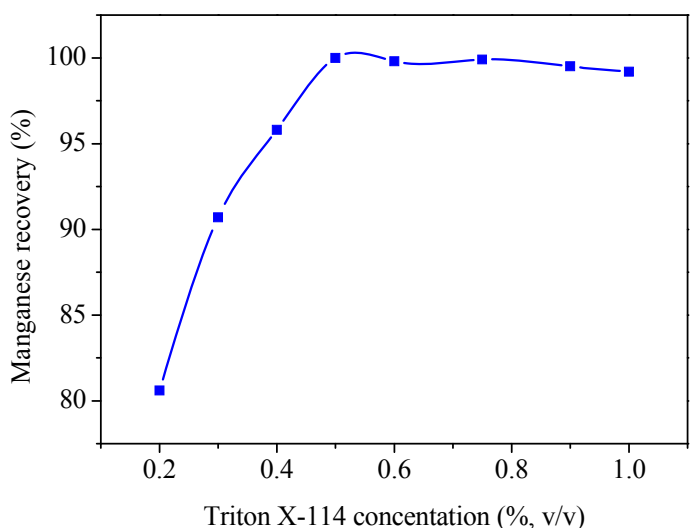

FIGURE IV. EXTRACTION EFfICIENCY OF THE COMPLEX AS A FUNCTION OF TRITON X-114 CONCENTRATION. EXPERIMENTAL CONDITIONS: $\mathrm{MN}^{2+}\left(100 \mathrm{NG} \cdot \mathrm{ML}^{-1}\right), 4 \times 10^{-5}$ $\mathrm{MOL} \cdot \mathrm{L}^{-1}$ PAN AND PH 9.

\section{E. Incubation Time and Temperature}

In order to get ration extraction, we also investigated other experimental conditions such as incubation temperature and incubation time. It is appropriate to use the shortest incubation time and the lowest incubation temperature probable. The dependency of extraction recovery to the incubation time and temperature was investigated in the range 5-30 $\mathrm{min}$ and 30 $65{ }^{\circ} \mathrm{C}$, respectively. The results showed that an equilibration time of $15 \mathrm{~min}$. And $50{ }^{\circ} \mathrm{C}$ were enough to indicate ration extraction.

\section{F. Interference Study}

The potential interference from co-exist positive ions was carefully studied with $100 \mathrm{ng} \cdot \mathrm{mL}^{-1} \mathrm{Mn}^{2+}$ so that it can prove the superior selectivity of the proposed method. The investigation of interferences with the determination of $\mathrm{Mn}^{2+}$ arising from other interfering species in the cloud point extraction was tabulated in table 1. These results prove that the general coexisting positive ions did not have a prominent effect on the separation and determination of the $\mathrm{Mn}^{2+}$. Therefore, the effects of other ions at given concentrations are ignorable.

TABLE I. INVESTIGATION OF INTERFERENCES FROM CO-EXISTING METAL IONS FOR THE DETERMINATION OF $100 \mathrm{NG} \cdot \mathrm{ML}^{-1} \mathrm{MN}^{2+}$ BY USING CPE PRECONCENTRATION FOLLOWED BY UV-VIS SPECTROPHOTOMETER DETERMINATION.

\begin{tabular}{|c|c|c|}
\hline Iron & Interference/metal ratio & Recovery (\%) \\
\hline $\mathrm{Mg}(\mathrm{II})$ & 1000 & 98.2 \\
\hline $\mathrm{Cu}(\mathrm{II})$ & 100 & 99.6 \\
\hline $\mathrm{Zn}(\mathrm{II})$ & 10 & 95.5 \\
\hline $\mathrm{Pb}(\mathrm{II})$ & 20 & 90.6 \\
\hline $\mathrm{Fe}(\mathrm{III})$ & 50 & 98.1 \\
\hline $\mathrm{Na}(\mathrm{I})$ & 2000 & 100.1 \\
\hline $\mathrm{Ni}(\mathrm{II})$ & 200 & 97.2 \\
\hline $\mathrm{Ba}(\mathrm{II})$ & 2000 & 96.7 \\
\hline $\mathrm{K}(\mathrm{I})$ & 5000 & 101 \\
\hline $\mathrm{Ca}(\mathrm{II})$ & 1000 & 100.3 \\
\hline
\end{tabular}

\section{G. Analytical figures of Merit}

Under the optimal conditions, the analytical performance of the proposed method was studied. The calibration graph was linear from 15 to $500 \mathrm{ng} \cdot \mathrm{mL}^{-1}$ with a correlation coefficient of 0.9988. The corresponding equation was found to be $\mathrm{A}$ $=0.00223 \mathrm{C}+0.001863$, where $\mathrm{A}$ is the absorbance and $\mathrm{C}$ is the manganese concentration in $\mathrm{ng} \cdot \mathrm{mL}^{-1}$. The limits of detection (LODs, $3 \sigma$ ) were $5.0 \mathrm{ng} \cdot \mathrm{mL}^{-1}$ for $\mathrm{Mn}^{2+}$. Enrichment factor was 35. The precision of (RSD) the CPE procedure was found to be $3.2 \%$ for $\mathrm{Mn}^{2+}\left(100 \mathrm{ng} \cdot \mathrm{mL}^{-1}, \mathrm{n}=11\right)$.

\section{H. Application}

In order to evaluate the dependability of the method, it was applied for the determination of $\mathrm{Mn}^{2+}$ in three natural water samples including river water(Huatan River), river water(Jialing River) and tap water(Xihua normal university). The results (Table2 and Table3) show that the proposed CPE method can be successfully applied for the recovery, preconcentration and determination of $\mathrm{Mn}$ ( II )in the tested water samples. 
TABLE II. DETERMINATION OF MANGANESE IN THE WATER SAMPLES BY THE PROPOSED METHOD.

\begin{tabular}{|c|c|c|c|c|}
\hline \multirow{2}{*}{ Sample } & \multicolumn{3}{|c|}{ Manganese $\left(\mathbf{n g} \cdot \mathbf{m L}^{-\mathbf{1}}\right.$ ) } & \multirow{2}{*}{$\begin{array}{c}\text { Recovery } \\
\text { (\%) }\end{array}$} \\
\cline { 2 - 5 } & Added & Found & R.S.D (\%) & - \\
\hline \multirow{3}{*}{ Tap water } & 0 & 27.5 & 1.5 & 100.2 \\
\cline { 2 - 5 } & 100 & 127.7 & 1.7 & 99.8 \\
\cline { 2 - 5 } & 400 & 427.0 & 1.2 & - \\
\hline \multirow{3}{*}{$\begin{array}{c}\text { River water } \\
\text { (Huatan River) }\end{array}$} & 100 & 148.1 & 1.3 & 99.6 \\
\cline { 2 - 5 } & 400 & 440.9 & 1.6 & 98.1 \\
\hline \multirow{2}{*}{$\begin{array}{c}\text { River water } \\
\text { (Jialing Raiver) }\end{array}$} & 100 & 149.6 & 1.5 & 99.9 \\
\cline { 2 - 5 } & 400 & 454.4 & 1.7 & 101.2 \\
\hline
\end{tabular}

TABLE III. DETERMINATION OF MANGANESE IN THE SOIL SAMPLE BY THE PROPOSED METHOD.

\begin{tabular}{|c|c|c|c|c|}
\hline \multirow{2}{*}{ Sample } & \multicolumn{3}{|c|}{ Manganese $\left(\mathbf{n g} \cdot \mathbf{m L}^{-\mathbf{1}}\right.$ ) } & \multirow{2}{*}{$\begin{array}{c}\text { Recovery } \\
\text { (\%) }\end{array}$} \\
\cline { 2 - 5 } & Added & Found & R.S.D (\%) & - \\
\hline \multirow{3}{*}{ Mountain soil } & 0 & 2.944 & 2.8 & 97.7 \\
\cline { 2 - 5 } & 100 & 4.906 & 3.1 & 100.1 \\
\cline { 2 - 5 } & 400 & 10.976 & 2.4 & - \\
\hline \multirow{3}{*}{ Garden soil } & 0 & 3.234 & 1.7 & 101.5 \\
\cline { 2 - 5 } & 100 & 5.258 & 2.5 & 99.5 \\
\cline { 2 - 5 } & 400 & 11.258 & 2.9 & - \\
\hline \multirow{3}{*}{ Filed soil } & 0 & 3.46 & 3.0 & 100.3 \\
\cline { 2 - 5 } & 100 & 5.416 & 2.3 & 98.6 \\
\cline { 2 - 5 } & 400 & 11.398 & 2.8 & \\
\hline
\end{tabular}

\section{CONCLUSIONS}

The reagent PAN was successfully applied in a CPE procedure for determination of trace amounts of manganese in environmental sample by UV-vis spectrophotometer. This work provides a simple, high sensitivity and high selectivity, and non-polluting technology for the preconcentration and determination of trace manganese metals. Triton X-114 is of relative low-cost and low toxicity. PAN is a very stable and fairly selective complexing reagent. Due to good analytical characteristics, the proposed $\mathrm{CPE}$ procedure has been demonstrated to be very interesting for trace manganese iron analysis method.

\section{ACKNOWLEDGMENT}

This work was supported by the National Natural Science Foundation of China (no. 21277109) and the Program for Young Scientific and Technological Innovative Research Team in Sichuan Province (2014TD0020).

\section{REFERENCES}

[1] F. Shemirani, R. M. Jamali, and R. R. Kozani, "Cloud Point Extraction and Preconcentration for the Determination of $\mathrm{Cu}$ and $\mathrm{Ni}$ in Natural
Water by Flame Atomic Absorption Spectrometry," Separation Science and Technology, vol. 41,pp. 3065-3077, 2006.

[2] R. Ansari, T. G. Kazi, M. K. Jamali, M. B. Arain, S. T. Sherazi, N. Jalbani, and H. I. Afridi, "Improved extraction method for the determination of iron, copper, and nickel in new varieties of sunflower oil by atomic absorption spectroscopy," J AOAC Int, vol. 91,pp. 400-7, 2008.

[3] T. G. Kazi, N. Jalbani, N. Kazi, M. B. Arain, M. K. Jamali, H. I. Afridi, G. A. Kandhro, R. A. Sarfraz, A. Q. Shah, and R. Ansari, "Estimation of toxic metals in scalp hair samples of chronic kidney patients," Biol Trace Elem Res, vol. 127,pp. 16-27, 2009.

[4] S. L. Ferreira, A. S. Souza, G. C. Brandao, H. S. Ferreira, W. N. dos Santos, M. F. Pimentel, and M. G. Vale, "Direct determination of iron and manganese in wine using the reference element technique and fast sequential multi-element flame atomic absorption spectrometry," Talanta, vol. 74,pp. 699-702, 2008.

[5] L. Soko, L. Chimuka, E. Cukrowska, and S. Pole, "Extraction and preconcentration of manganese(II) from biological fluids (water, milk and blood serum) using supported liquid membrane and membrane probe methods," Analytica Chimica Acta, vol. 485,pp. 25-35, 2003.

[6] J. F. van Staden, L. V. Mulaudzi, and R. I. Stefan, "Speciation of Mn(II) and $\mathrm{Mn}(\mathrm{VII})$ by on-line spectrophotometric sequential injection analysis," Analytica Chimica Acta, vol. 499,pp. 129-137, 2003.

[7] M. A. Akl, "Preconcentration extractive separation, speciation and spectrometric determination of iron(III) in environmental samples," Microchemical Journal, vol. 75,pp. 199-209, 2003.

[8] C. Dittfurth, E. Ballesteros, M. Gallego, and M. Valcárcel, "On-line precipitation/dissolution system for the preconcentration and determination of manganese traces by atomic absorption spectrometry," Spectrochimica Acta Part B: Atomic Spectroscopy, vol. 51,pp. 19351941, 1996.

[9] S. Baytak, and A. R. Turker, "The use of Agrobacterium tumefacients immobilized on Amberlite XAD-4 as a new biosorbent for the column preconcentration of iron(III), cobalt(II), manganese(II) and chromium(III)," Talanta, vol. 65,pp. 938-45, 2005.

[10] N. Pourreza, and H. Z. Mousavi, "Solid phase preconcentration of iron as methylthymol blue complex on naphthalene-tetraoctylammonium bromide adsorbent with subsequent flame atomic absorption determination," Talanta, vol. 64,pp. 264-7, 2004.

[11] M. E. Mahmoud, and M. S. M. Al Saadi, "Selective solid phase extraction and preconcentration of iron(III) based on silica gelchemically immobilized purpurogallin," Analytica Chimica Acta, vol. 450,pp. 239-246, 2001.

[12] V. A. Lemos, P. X. Baliza, A. L. de Carvalho, R. V. Oliveira, L. S. Teixeira, and M. A. Bezerra, "Development of a new sequential injection in-line cloud point extraction system for flame atomic absorption spectrometric determination of manganese in food samples," Talanta, vol. 77,pp. 388-93, 2008.

[13] E. K. Paleologos, D. L. Giokas, and M. I. Karayannis, "Micellemediated separation and cloud-point extraction," TrAC - Trends in Analytical Chemistry, vol. 24,pp. 426-436, 2005.

[14] A. Sanz-Medel, M. d. R. Fernandez de la Campa, E. B. Gonzalez, and M. L. Fernandez-Sanchez, "Organised surfactant assemblies in analytical atomic spectrometry," Spectrochimica Acta Part B: Atomic Spectroscopy, vol. 54,pp. 251-287, 1999.

[15] J. Ning, Y. Jiao, J. Zhao, L. Meng, and Y. Yang, "Cloud point extraction-flame atomic absorption spectrometry method for preconcentration and determination of trace cadmium in water samples," Water Sci Technol, vol. 70,pp. 605-11, 2014.

[16] M. F. Silva, E. S. Cerutti, and L. D. Martinez, "Coupling cloud point extraction to instrumental detection systems for metal analysis," Microchimica Acta, vol. 155,pp. 349-364, 2006. 